\title{
PENILAIAN KUALITAS ESTETIKA VISUAL LANSKAP PADA KORIDOR JALAN RAYA BANDARA INTERNASIONAL SOEKARNO- HATTA, TANGERANG
}

\section{Assessment the Visual Aesthetic Quality of the Landscape in Soekarno-Hatta International Airport Street Corridor}

\author{
Olivia Dais Agustin \\ Program Studi Arsitektur Lanskap \\ Universitas Trisakti \\ Email: daisolivia@gmail.com
}

Nur Intan Simangunsong

Program Studi Arsitektur Lanskap

Universitas Trisakti

Email: nurintan@trisakti.ac.id

\section{Rustam Hakim}

Program Studi Arsitektur Lanskap

Universitas Trisakti

Email: bangrus04@gmail.com

\begin{abstract}
Soekarno-Hatta International Airport, which is one of the gateways to Indonesia, has a visual potential capable to providing multi-images both locally, nationally and internationally. The Soekarno-Hatta International Airport highway corridor landscape has a role in building environmental character and visual aesthetics in presenting the image and identity of the region. Nowadays, the condition of the road corridor is not yet optimal in presenting an attractive image of the area. Then, the purpose of this study is to assess the visual aesthetic quality of the landscape on the highway corridor of Soekarno-Hatta International Airport and determine areas that have the potential for landscape visual aesthetics. The research method in this study is descriptive-qualitative method, while data collection through a questionnaire, the data that has been collected will be measured the visual aesthetic value of the landscape using likert scale analysis techniques. The results of assessment produce areas show the potential for visual aesthetic landscapes of street corridor. Thus, the visual character of the BISH Highway corridor landscape is able to present an attractive regional image both locally, nationally and internationally.
\end{abstract}

Keywords: potential, regional image, street corridor landscape, visual aesthetic value

\section{PENDAHULUAN}

\section{Latar Belakang}

Bandara Internasional Soekarno-Hatta (BISH) merupakan salah satu gerbang untuk menuju Indonesia, bandara tersebut mempunyai potensi visual yang mampu memberikan multi-image baik secara lokal, nasional maupun internasional. Kawasan BISH memiliki koridor jalan yang cukup luas, salah satu koridor yang dapat dilihat di kawasan ini adalah koridor Jalan Raya BISH yang berdekatan dengan Tugu Soekarno-Hatta. Alasan pemilihan lokasi ini dikarenakan lanskap koridor Jalan Raya BISH terlihat mempunyai potensi sebagai lanskap yang berperan dalam membangun karakter lingkungan, spasial dan estetika visual dalam menampilkan citra dan identitas kawasan (Hakim, 2006). Namun, saat ini kondisi koridor jalan tersebut belum optimal dalam menampilkan citra kawasan yang menarik. Hal ini dapat dilihat pada kondisi eksisting dimana belum terdapat elemen estetika visual lanskap yang menarik. Peran Arsitek Lanskap sangat dibutuhkan dalam penilaian dan pengembangan lanskap koridor jalan demi terwujudnya koridor Jalan Raya BISH yang mampu menampilkan citra kawasan yang menarik secara lokal, nasional dan internasional.

\section{Tujuan Penelitian}

Tujuan dari penelitian ini adalah untuk menilai kualitas estetika visual lanskap pada koridor Jalan Raya BISH serta menentukan area-area yang mempunyai potensi estetika visual lanskap yang baik.

\section{STUDI PUSTAKA}

Sistem estetika visual lanskap koridor jalan mencakup rangkaian pandangan koridor (optic), reaksi pengamat dengan ruang koridor (place), dan ragam elemen yang mendukung tampilan koridor (content). Sedangkan aspek yang dapat mempengaruhi kualitas estetika visual menjadi satu kesatuan dalam satu kajian kualitas visual yaitu keindahan yang berdasarkan aspek-aspek: (a) kesatuan, (b) proporsi, (c) skala, (d) keseimbangan, (e) irama, (f) warna, dan (g) urutan (Booth, 1983).

Elemen-elemen lanskap terdiri dari (a) permukaan tanah, (b) unsur tanaman, (c) bangunan, (e) perkerasan, (f) struktur tapak dan (g) air. Sedangkan elemen visual lanskap koridor jalan yang secara spesifik, elemen fisik dari sebuah pandangan yang akan terekam dalam pengamatan seseorang termasuk di dalamnya adalah: (a) bentuk jalan, (b) derajat keterlingkupan, (c) pohon pada sisi jalan, (d) pola arsitektural, (e) pola aktivitas. Sebuah koridor jalan mempunyai elemen-elemen pembentuk sebuah koridor jalan, elemen tersebut adalah (a) jarak, (b) sirkulasi pejalan kaki, (c) trotoar, (d) pola jalan dan sirkulasi (Cullen, 1961).

Penelitian ini menggunakan penilaian dari rangkaian pandangan koridor (optic), reaksi pengamat (place), dan ragam elemen pendukung (content) (Booth, 1983; Cullen 1961). Hal tersebut akan dijadikan satu penilaian menggunakan skala likert dengan perbandingan nilai 1 sampai dengan 5 .

\section{METODE PENELITIAN}

Metode penelitian dalam studi ini adalah deskriptifkualitatif, sedangkan pengumpulan data menggunakan kuisioner, data yang telah terkumpul diukur nilai estetika visual lanskap menggunakan teknik analisis skala likert 
(Smardon, 1986). Hasil analisis dari penilaian tersebut menghasilkan area-area yang mempunyai potensi estetika visual lanskap pada obyek studi.

Penilaian kualitas estetika visual lanskap (Sugiyono, 2017) menggunakan teknik kuisioner, responden menilai menggunakan skala perbandingan 1 s.d. 5 dengan interval bobot nilai atau skor likert (Tabel 1) dan kriteria penilaian (Tabel 2)

Tabel 1. Bobot Penilaian

\begin{tabular}{cc}
\hline Nilai & Bobot Nilai \\
\hline 5 & Sangat Menarik (SM) \\
4 & Menarik (M) \\
3 & Cukup Menarik (CM) \\
2 & Kurang Menarik (KM) \\
1 & Tidak Menarik (TM) \\
\hline
\end{tabular}

Berikut merupakan penggunaan rumus perhitungan total skala likert, yaitu:

- Jawaban hasil $(\mathrm{SM})=(\mathrm{n})$ responden $\times 5=$

- Jawaban hasil $(\mathrm{M})=(\mathrm{n})$ responden $\times 4=$

- Jawaban hasil $(\mathrm{CM})=(\mathrm{n})$ responden $\times 3=$

- Jawaban hasil $(\mathrm{KM})=(\mathrm{n})$ responden $\times 2=$

- Jawaban hasil $(\mathrm{TM})=(\mathrm{n})$ responden $\times 1=\ldots$

Total Skor $=$ Jumlah Total Responden $\times$ Bobot Nilai Maksimum= Jumlah Responden $\times$ Skor Tertinggi Likert Indeks $(\%)=$ Total Skor / Skor Maksimum x 100

Tabel 2. Indeks Kriteria Penilaian

\begin{tabular}{cc}
\hline Indeks & Kriteria \\
\hline $0 \%-20 \%$ & Tidak Menarik \\
$21 \%-40 \%$ & Kurang Menarik \\
$41 \%-60 \%$ & Cukup Menarik \\
$61 \%-80 \%$ & Menarik \\
$81 \%-100 \%$ & Sangat Menarik
\end{tabular}

\section{HASIL DAN PEMBAHASAN}

\section{Deskripsi Obyek Studi}

Lokasi Jalan Raya BISH terletak di dalam kawasan Bandara Internasional Soekarno-Hatta, Tangerang, Banten - Indonesia (Gambar 1-3). Koridor Jalan Raya BISH yang merupakan salah satu koridor jalan yang terdapat pada kawasan BISH memiliki koridor jalan sepanjang $\pm 26 \mathrm{~km}$. Berdasarkan masterplan di atas, koridor Jalan Raya BISH merupakan jalan penghubung antar terminal pada BSIH, yaitu terminal 1 sampai terminal 4, terminal kargo, stasiun kereta bandara serta gedung-gedung operasional. Alasan pemilihan lokasi ini dikarenakan terlihat mempunyai potensi sebagai lanskap yang berperan dalam membangun karakter lingkungan, spasial dan estetika visual dalam menampilkan citra kawasan di perkotaan. Oleh karena itu, lanskap koridor jalan tersebut diharapkan dapat memberikan pengalaman yang menyenangkan dari suatu titik ke titik yang lain sehingga diperlukan penilaian estetika visual dan penentuan area-area yang mempunyai potensi nilai estetika visual yang disesuaikan dengan fungsi utama koridor jalan (Bell, 1993; Lestari dan Gunawan, 2014). Pertimbangan pemilihan titik area penilaian kualitas estetika visual lanskap karena mempunyai potensi dan area yang banyak dilintasi pengunjung Bandara ditampilkan pada Gambar 4.

\section{Analisis Demografi}

Berdasarkan metode teknik kuisioner yang telah dilaksanakan, merupakan presentasi hasil dari kuisioner yang terkumpul dari 77 responden (Gambar 4, 5 dan 6).

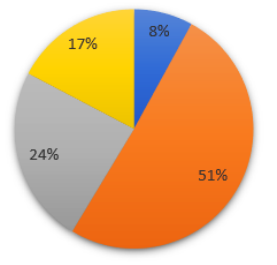

Bekerja dikawasan Bandara Soetta

Gambar 4. Klasifikasi Tujuan Kunjungan Responden



Gambar 5. Klasifikasi Sarana Transportasi Responden
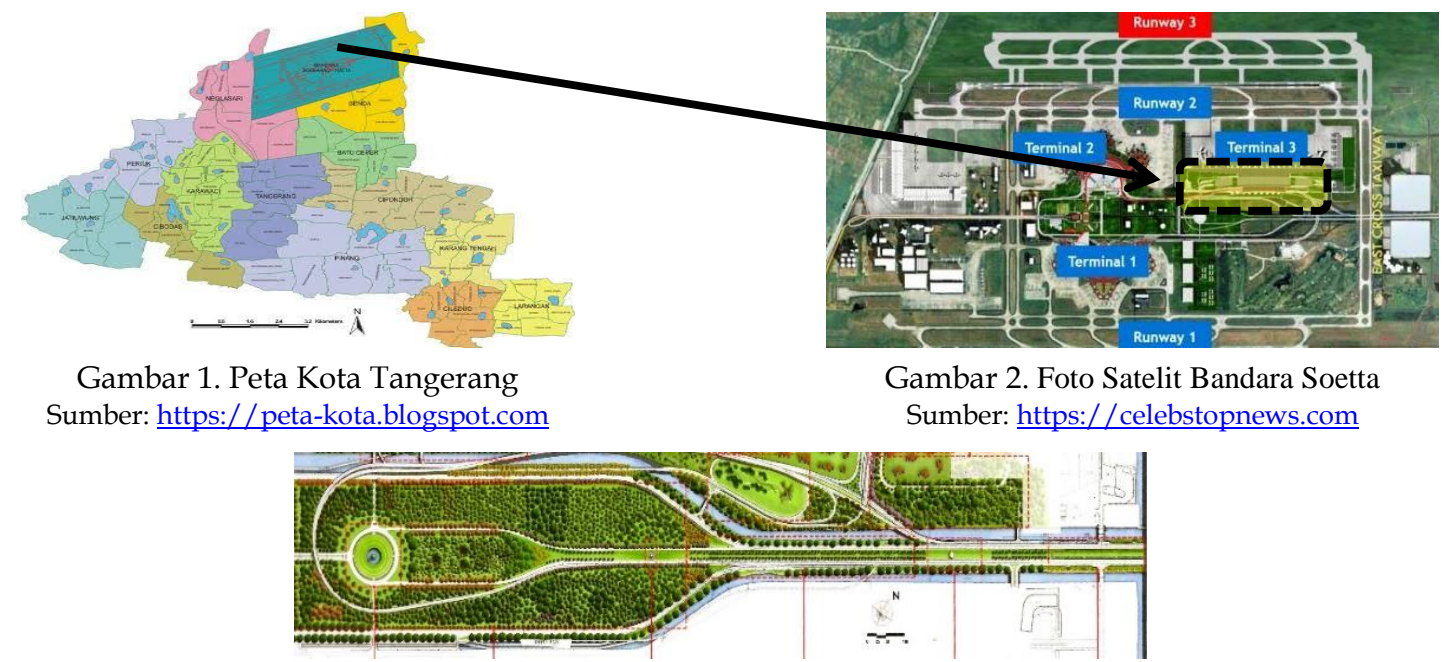

Gambar 3. Masterplan Koridor Jalan Raya Bandara Soetta Sumber: Waskita-Penta 


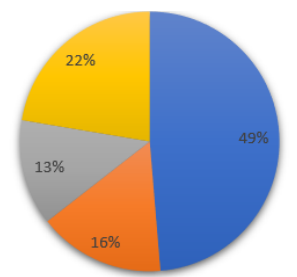

- Bundaran Tugu Soekarno-Hatta - Tugu Garuda Sakti = Pohon Peneduh = Ely Over Terminal 3

Gambar 6. Klasifikasi Elemen Visual Eksisting yang Menarik Bagi Responden
Data yang telah terkumpul dari hasil kuisioner di atas, kemudian dilakukan analisis pengolahan data menggunakan teknik skala likert. Hal ini akan menunjukkan hasil indeks setiap titik area termasuk dalam kategori sangat menarik, menarik, cukup menarik, kurang menarik atau sangat kurang menarik. Hasil indeks yang paling tinggi termasuk dalam kategori mempunyai potensi yang besar terhadap estetika visual lanskap koridor Jalan Raya BISH.

Berikut merupakan hasil analisis pengolahan data dengan menggunakan teknik analisis skala likert:

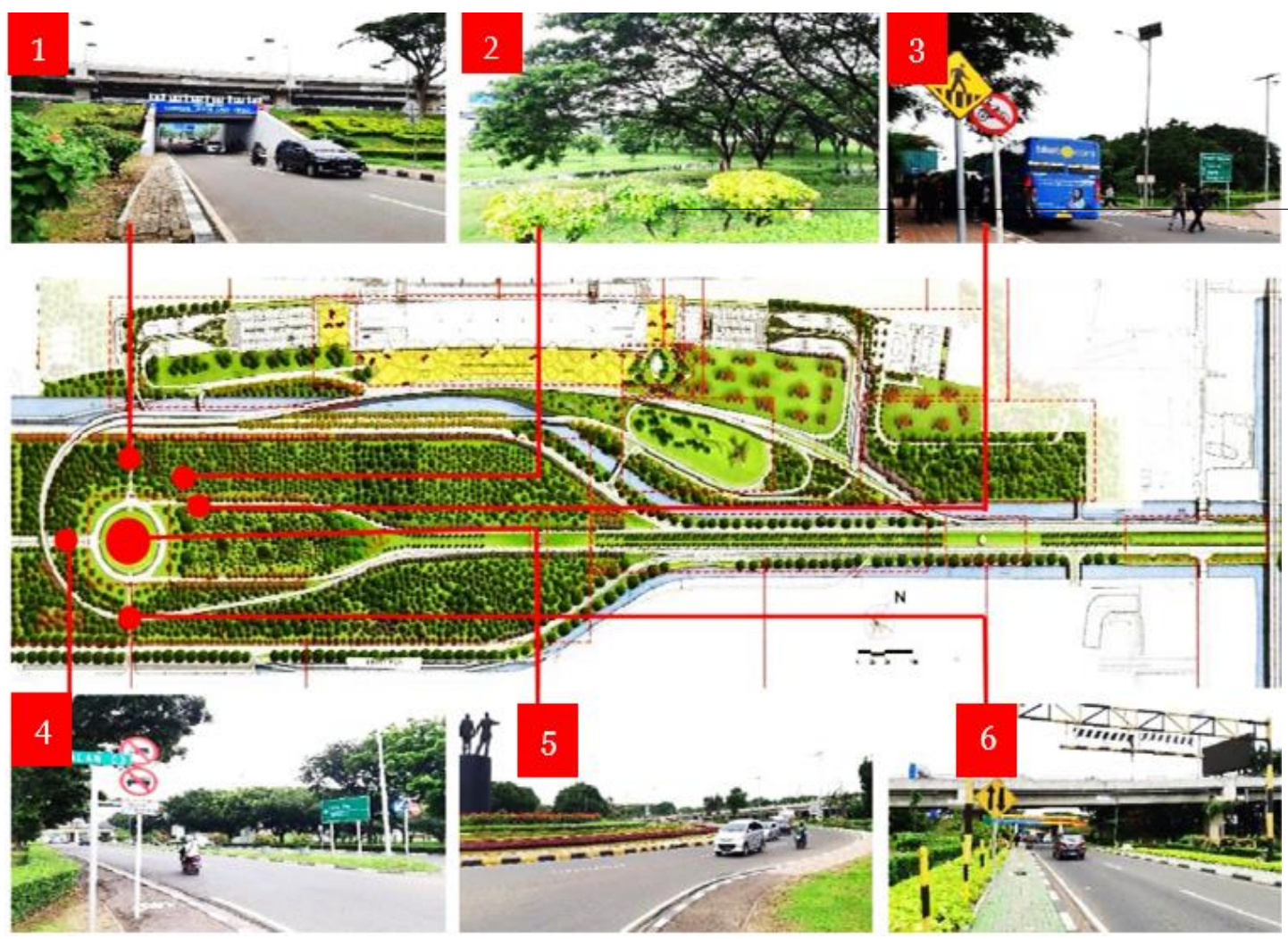

Gambar 4. Titik Area Penilaian Estetika Visual Lanskap

Berdasarkan gambar di atas, jenis tujuan responden mengunjungi tapak didominasi oleh tujuan menuju BSIH, dengan sarana transportasi roda empat, serta elemen visual eksisting yang menarik bagi responden didominasi oleh area Bundaran Tugu Soekarno-Hatta.

\section{Penilaian Kualitas Estetika Visual Lanskap}

Melalui metode Teknik kuisioner yang terkumpul, Tabel 3 merupakan hasil penilaian estetika visual lanskap Jalan Raya BISH responden.

Tabel 3. Hasil Kuisioner yang Terkumpul

\begin{tabular}{|c|c|c|c|c|}
\hline \multirow{2}{*}{ No } & \multicolumn{4}{|c|}{ Nilai Estetika Visual } \\
\hline & 1 & 3 & 4 & 5 \\
\hline 1. Jalur Menuju Terminal 3 Ultimate & 2 & 21 & 33 & 14 \\
\hline 2. Area Hutan Penghijauan & 9 & 14 & 35 & 17 \\
\hline 3. Area Shelter Bus Bandara & $7 \quad 15$ & 32 & 19 & 4 \\
\hline $\begin{array}{l}\text { 4. Jalur Menuju Gedung } \\
\text { Operasional Bandara }\end{array}$ & 10 & 38 & 24 & 4 \\
\hline $\begin{array}{l}\text { 5. Area Bundaran Tugu Soekarno- } \\
\text { Hatta }\end{array}$ & 2 & 10 & 40 & 24 \\
\hline 6. Jalur Menuju Terminal Kargo & 11 & 30 & 30 & 5 \\
\hline
\end{tabular}

Tabel 4. Hasil Analisis Pengolahan Data

\begin{tabular}{clcc}
\hline No. & \multicolumn{1}{c}{ Area } & Nilai $(\%)$ & Kriteria \\
\hline 1. & $\begin{array}{l}\text { Jalur Menuju Terminal } \\
\text { 3 Ultimate }\end{array}$ & 72.98 & Menarik \\
2. & $\begin{array}{l}\text { Area Hutan } \\
\text { Penghijauan }\end{array}$ & 74.55 & Menarik \\
3. & $\begin{array}{l}\text { Area Shelter Bus } \\
\text { Bandara }\end{array}$ & 59.48 & $\begin{array}{c}\text { Cukup } \\
\text { Menarik }\end{array}$ \\
4. & $\begin{array}{l}\text { Jalur Menuju Gedung } \\
\text { Operasional Bandara }\end{array}$ & 65.19 & Menarik \\
5. & $\begin{array}{l}\text { Area Bundaran Tugu } \\
\text { Soekarno-Hatta }\end{array}$ & 81.81 & $\begin{array}{c}\text { Sangat } \\
\text { Menarik }\end{array}$ \\
6. & $\begin{array}{l}\text { Jalur Menuju } \\
\text { Terminal Kargo }\end{array}$ & 67.01 & Menarik \\
\hline
\end{tabular}

\section{Penentuan Area Berpotensi Estetika Visual Lanskap}

Berdasarkan hasil pengolahan data pada Tabel 3 di atas, terdapat 4 area yang berkriteria "menarik", 1 area berkriteria "sangat menarik" dan 1 area berkriteria "sangat tidak menarik". Hal tersebut dapat disimpulkan bahwa 


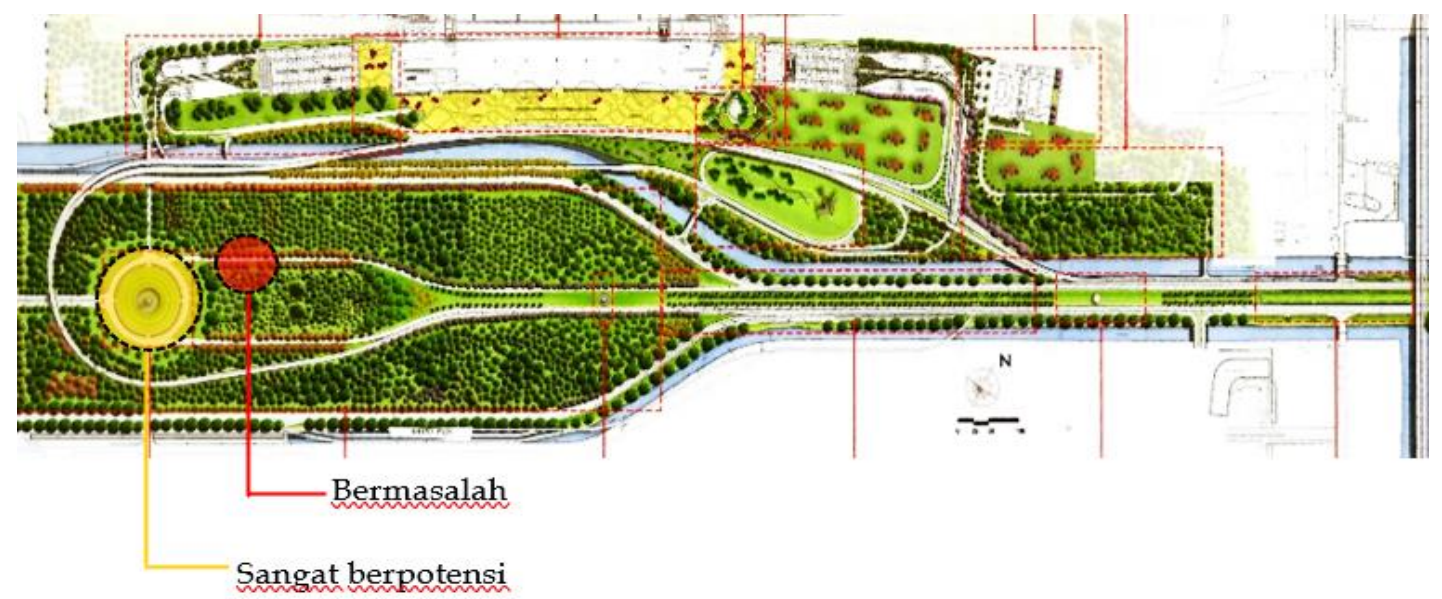

Gambar 5. Titik Area Sangat Berpotensi dan Bermasalah di Bandara Soekarno - Hatta

area yang sangat berpotensi dalam estetika visual lanskap terdapat pada area Bundaran Tugu SoekarnoHatta sedangkan untuk area yang mempunyai permasalahan adalah pada area Shelter Bus Bandara.

\section{Gagasan Pengembangan Lanskap}

Berdasarkan penilaian estetika visual lanskap di atas, maka gagasan yang akan diterapkan pada area yang sangat berpotensi (Bundaran Tugu Soekarno-Hatta) adalah mengoptimalkan atraksi lanskap eksisting dengan pengembangan seperti menambahkan elemen visual yang mampu menjadikan area tersebut lebih menarik (Hakim, 2006; Nurmasari, 2008). Sedangkan gagasan untuk area yang kurang berpotensi (Shelter Bus Bandara) adalah meningkatkan kualitas atraksi lanskap shelter agar pengguna dapat merasakan estetika visual lanskap yang menarik dan untuk 4 area lainnya (area hutan penghijauan, jalur menuju Terminal 3 Ultimate, jalur menuju gedung operasional bandara, dan jalur menuju terminal kargo) yang berpotensi, pada area tersebut diberi gagasan pengembangan atraksi agar pengguna jalan yang melintas akan menikmati estetika visual lanskap yang menarik dan menyenangkan sebagai peningkatan jasa lanskap (Kaswanto et. al., 2017; Faradilla et. al., 2018).

\section{Hasil Temuan Penelitian}

Setelah melakukan analisis hasil penelitian di atas, dihasilkan temuan penelitian. Temuan penelitian ini terbagi menjadi 3 zona (Tabel 5).

Tabel 5. Hasil Temuan Penelitian

\begin{tabular}{cll}
\hline No. & \multicolumn{1}{c}{ Area } & \multicolumn{2}{c}{ Hasil Temuan Penelitian } \\
\hline 1. Jalur Menuju & - & Dibutuhkan penatan vegetasi \\
Terminal 3 & $\begin{array}{l}\text { lanskap yang beragam, untuk } \\
\text { menciptakan atraksi lanskap }\end{array}$ \\
Ultimate & yang lebih menarik dan tidak \\
& membosankan bagi pengguna \\
& Dibutuhkan pemilihan warna \\
& vegetasi yang beragam, seperti \\
& yang berbunga indah agar visual \\
& lanskap pada tapak terkesan \\
& lebih estetik. \\
& Dibutuhkan beberapa signage \\
& berupa ornamen lokal untuk \\
& menghindari kesan yang \\
& monoton. \\
\hline
\end{tabular}

\begin{tabular}{ccc} 
No. & Area & \multicolumn{2}{c}{ Hasil Temuan Penelitian } \\
\hline 2. & Area Hutan & Dibutuhkan pola penataan \\
Penghijauan & tanaman lanskap yang menarik \\
& serta pemilihan warna tanaman \\
& yang beragam seperti tanaman \\
& yang berbunga/berdaun indah \\
& untuk memberikan nilai visual \\
& lanskap yang lebih estetik. \\
& Dibutuhkan elemen visual yang \\
& berpotensi visual pada tapak, \\
& seperti wetland buatan yang \\
& berfungsi juga sebagai bio- \\
& filtration untuk mengontrol iklim \\
& mikro pada tapak.
\end{tabular}

3. Area Shelter - Dibutuhkan pengembangan Bus Bandara desain pada area shelter yang lebih estetik dan menambahkan ornament lokal untuk memberikan citra Kawasan

Dibutuhkan pola penataan tanaman lanskap yang menarik serta pemilihan warna tanaman yang beragam seperti tanaman yang berbunga/berdaun indah untuk memberikan nilai visual lanskap yang lebih estetik.

4. Jalur Menuju - Dibutuhkan pola penataan Gedung tanaman lanskap yang menarik Operasional serta pemilihan warna tanaman yang beragam seperti tanaman yang berbunga/berdaun indah untuk memberikan nilai visual lanskap yang lebih estetik

Dibutuhkan beberapa signage berupa ornamen lokal untuk menghindari kesan yang monoton pada jalur.

5. Area Dibutuhkan pengembangan Bundaran desain bundaran dan Tugu penambahan unsur air untuk Soekarno- mengontrol iklim mikro, Hatta dikarenakan pada area bundaran merupakan pusat pertemuan mobilisasi transportasi dari berbagai arah

Dibutuhkan pola penataan tanaman lanskap yang menarik 


\begin{tabular}{lll} 
No. Area & \multicolumn{1}{c}{ Hasil Temuan Penelitian } \\
& serta pemilihan warna tanaman \\
& yang beragam seperti tanaman \\
& yang berbunga/berdaun indah \\
& untuk memberikan nilai visual \\
& lanskap yang lebih estetik \\
& Jalur Menuju & Dibutuhkan pola penatan \\
Terminal & tanaman lanskap yang menarik \\
& serta pemilihan warna tanaman \\
& beragam untuk memberikan nilai \\
& visual lanskap yang lebih estetik \\
& terutama pada area median jalan \\
& Dibutuhkan beberapa signage \\
& berupa ornamen lokal untuk \\
& menghindari kesan yang \\
& monoton
\end{tabular}

\section{SIMPULAN}

Merujuk penelitian perhitungan nilai kualitas estetika visual lanskap yang sudah dilakukan, masih terdapat area yang mempunyai nilai "cukup" yaitu pada area Shelter Bus Bandara, hal tersebut perlu menjadi perhatian dan diadakan pengoptimalan atraksi lanskap area shelter untuk meningkatkan kualitas visual yang lebih menarik. Sedangkan pada area yang mempunyai potensi yang lebih tinggi yaitu pada area Bundaran Tugu SoekarnoHatta, direkomendasikan untuk dilakukan pengoptimalan area bundaran, terlebih area bundaran merupakan pusat pertemuan aktivitas mobilisasi transportasi pada kawasan BSIH.

Untuk lebih terlihat image/citra kawasan, perlu diadakan signage berupa ornamen lokal pada beberapa titik untuk menjadikan tapak sebagai lanskap yang memberikan first impression yang menarik dan menyenangkan baik secara lokal, nasional maupun internasional.

\section{DAFTAR PUSTAKA}

Bell, S. 1993. Elements in Visual Design in the Landscape: Second Edition. London and New York: Spon Press.

Booth, N. K. 1983. Basic Element of Landscape Architectural Design. Illonis: Wavelands Press.

Cullen, G. 1961. The Concise Townscape. Butterworth Heinemann: University Press, Cambridge.

Faradilla, E., Kaswanto, R.L., Arifin, H. S. 2018. Analisis Kesesuaian Lahan untuk Ruang Terbuka Hijau dan Ruang Terbuka Biru di Sentul City, Bogor. Jurnal Lanskap Indonesia, 9(2), 101-109. https://doi.org/10.29244/jli.2017.9.2.101-109.

Hakim, R. 2006. Rancangan Visual Lanskap Jalan. Jakarta: Bumi Aksara.

Kaswanto, R. L., Filqisthi, T. A., Choliq, M. B. S. 2017. Revitalisasi Pekarangan Lanskap Perdesaan Sebagai Penyedia Jasa Lanskap untuk Meningkatkan Kesejahteraan Masyarakat. Jurnal Lanskap Indonesia, 8(1), 50-60. https://doi.org/10.29244/jli.v8i1.17638.

Lestari, G., Gunawan, A. 2014. Pengaruh Bentuk Kanopi Pohon terhadap Kualitas Estetika Lanskap Jalan. Jurnal Lanskap Indonesia, 2(1). https://doi.org/10.29244/jli.2010.2.1
Nurmasari, S. 2008. Hubungan Media Ruang Luar (Menggunakan Pencahayaan Buatan) dengan Kualitas Visual Koridor di Malam Hari Menurut Persepsi Masyarakat. Tesis. Semarang: Universitas Diponegoro

Smardon, R. 1986. Foundation for Visual Project Analysis. New York: John Wiley and Sons.

Sugiyono. 2017. Metode Penelitian Kuantitatif, Kualitatif dan RED. Bandung: Alfabeta. 